\title{
Prioridad impostergable: salud y calidad de vida infantojuvenil
} An urgent priority: Child and adolescent health and quality of life

La orientación esencial que guía estas reflexiones intenta fundamentalmente ayudar en la búsqueda de abordajes viables a la difícil situación que padecen en la actualidad millones de niños, niñas y adolescentes en nuestro país.

La motivación de compartir algunas sugerencias surgió como un impulso de volcar mi experiencia profesional pediátrica durante 62 años, en los ámbitos asistenciales público y privado, haber ejercido la docencia universitaria y comunitaria y realizado investigaciones clínicas y psicosociales. Accedí por los respectivos concursos a los distintos niveles escalafonarios; singular privilegio que siempre agradezco.

Resulta momento propicio para recordar a algunas personalidades paradigmáticas que me enseñaron a considerar la salud y la calidad de vida de la infancia y la adolescencia desde una perspectiva integral y como una realidad ineludible. Entre tantos, quiero destacar a: Juan Pedro Garrahan, eminente pediatra y notable autor de numerosas publicaciones; Florencio Escardó, protagonista fundamental en la historia de la pediatría argentina y Carlos Arturo Gianantonio, considerado de manera indiscutible el máximo maestro de la especialidad, y personalidad pletórica de valores morales y virtudes extraordinarias de sapiencia médica.

En nuestra ciudad merecen este recordatorio insoslayable Noel Humberto Sbarra, médico imbuido de profundas convicciones democráticas, sanitarista de fuste, pionero del cuidado integral y el bienestar de los niños y niñas abandonados, labor que desarrolló durante muchos años en la Casa Cuna e Instituto de Puericultura, hoy hospital que lleva su nombre; Juan Vicente Climent, profesional de incansable dedicación a la atención de recién nacidos y lactantes con patologías graves, no sabía de horarios prefijados, un verdadero ejemplo de laboriosidad en favor de la curación de las dolencias de la niñez. Abraham Rahman, docente por vocación y actitud, hizo de la enseñanza una misión humanística al servicio de los aprendices de este oficio difícil: lo más destacado de su enfoque sobre el cuidado de la salud infantojuvenil fue haber sido el primero en considerar los problemas emocionales y psicológicos como generadores de alteraciones de la calidad de vida.

Respecto a los funcionarios ministeriales de salud que, a mi criterio, desarrollaron una gestión acorde con las urgencias y necesidades de la infancia y los jóvenes, quiero mencionar a Carlos Bocalandro, Osvaldo Mammoni, Floreal Ferrara, Herminio Zatti e Ismael Pasaglia.

No puedo dejar de evocar en esta apretada síntesis a tantos y tantas profesionales de distintas disciplinas, trabajadores y trabajadoras de diferentes grupos ocupacionales, así como a los miembros de las organizaciones comunitarias (voluntariados, cooperadoras) que, con su labor cotidiana y comprometida, ayudaron y ayudan a asistir a niños, niñas y adolescentes, sanarlos, cuidarlos, acompañarlos, jugar y cooperar en momentos tan complejos para ellos, cuando están afectados por problemas de salud. Sin embargo, estos esfuerzos no alcanzan para aliviar circunstancias tan penosas. Existe incertidumbre, sensación de miedo y angustia ante una coyuntura no resuelta desde hace tanto tiempo, agravada hoy en día. Sirva de ejemplo que, según el INDEC, en este último trimestre la pobreza afectó al 40,9\% de la población, pero resulta mucho más alarmante si mencionamos que el $56,3 \%$ de este grupo tienen entre 0 y 14 años. Si a ello agregamos incumplimiento de sus derechos esenciales, desigualdades socioeconómicas múltiples, desorganización familiar, estimulación psicoafectiva insuficiente, deserción escolar alta, analfabetismo creciente, bajo nivel de educación formal de los padres, escasos controles de salud, esquemas de vacunación incompletos, vivienda precaria con hacinamiento y sin saneamiento básico, trabajo infantil insalubre, malos tratos y violencia de parte de adultos o de pares, abuso sexual infantojuvenil, escaso juego compartido, soledad, padres y madres desocupados o con trabajos informales, adicciones, consumo exagerado de televisión y computadoras, y otros tantos factores de vulnerabilidad que influyen desfavorablemente en una buena calidad de vida, vemos que dar respuesta a estos verdaderos flagelos, implica una titánica e inaplazable tarea que no podemos eludir. No hacerlo implicaría una deshumanización retrógrada.

Este deseo pretende que todos los adultos, cualquiera sea nuestro rol social, comencemos a entender que es una responsabilidad ética, social e histórica, comprender y proteger a todos los niños, niñas y adolescentes sin ningún tipo de 
discriminaciones, si queremos y aspiramos a un futuro mejor.

Será necesario poner en vigencia políticas sanitarias con criterio preventivo no homogeneizadas, adaptadas a las necesidades locales, regionales, provinciales y nacionales, que contribuyan a eliminar los desequilibrios que actualmente tanto los afectan. Es primordial mantener la salud infantojuvenil plena o restituirla si se la ha perdido. Para ello, resulta indispensable una inversión presupuestaria estatal que financie todos los requerimientos sanitarios, que se deberá mantener a futuro y por siempre. Es necesario también asegurar un salario digno para todos los trabajadores de los servicios de salud, sin excepción.

Acorde con un cambio de modelo asistencial que posibilite un mejoramiento de los padecimientos que sufre gran parte de la población infantojuvenil, propongo algunas acciones y estrategias simples que ayudarían en tal sentido:

- Cumplimentar en forma irrestricta la Convención de los Derechos de Niños, Niñas y Adolescentes, incorporada a la Constitución Nacional.

- Garantizar el acceso de todas las embarazadas a controles periódicos.

- Propiciar el parto institucional humanizado.

- Controlar al recién nacido de manera integral.

- Fomentar el amamantamiento inmediato al nacimiento de manera sistemática.

- Introducir la alimentación complementaria de semisólidos y sólidos entre los cuatro y seis meses de edad y mantener, de ser posible, la alimentación materna.

- Asegurar que todas las familias puedan acceder a la canasta básica de alimentos saludables.

- Realizar controles antropométricos (peso, talla y perímetro cefálico) periódicos y confeccionar las respectivas gráficas.

- Controlar el desarrollo evolutivo psicológico, motriz y adaptativo, y el lenguaje y personal social.

- Cumplimentar el calendario oficial de inmunizaciones para toda la población infantojuvenil.

- Conformar equipos de salud interdisciplinarios en todas las instituciones de salud infantojuveniles.

- Brindar pautas de desarrollo infantil temprano y formas de adquirirlas a todos los niños y niñas, incluidos quienes tienen capacidades diferentes.
- Diagnosticar las enfermedades prevalentes con criterio oportuno, anticipatorio y preventivo.

- Concretar la internación conjunta del niño con su madre o padre en forma obligatoria.

- Impedir el trabajo nocivo a edades no permitidas por la ley.

- Priorizar como esencial la atención primaria de la salud, puerta de entrada al sistema sanitario.

- Garantizar accesibilidad, equidad y calidad en la prestación de los servicios.

- Ampliar horarios de atención ambulatoria en los ámbitos públicos y privados.

- Reordenar las instituciones sanitarias por niveles de complejidad creciente.

- Posibilitar mecanismos de derivaciones eficaces y eficientes.

- Ofrecer educación sexual apropiada en todos los sectores de enseñanza.

- Propiciar vínculos afectivos trigeneracionales permanentes entre los niños, niñas y adolescentes y sus padres, madres, abuelos y abuelas.

- Evitar el uso acrítico de la tecnología en el diagnóstico de enfermedades y el encarnizamiento terapéutico.

- Promover entornos saludables de trabajo basados en la escucha, el consenso y la comunicación cordial entre el personal de salud tanto de instituciones públicas como privadas.

Quede en claro que estas sugerencias podrán no ser compartidas. Bienvenido el disenso democrático, que seguramente posibilitará la consideración de otras alternativas. Mancomunemos esfuerzos de familias, comunidades, instituciones y Estado y, con certeza, estas y otras propuestas podrán concretar la prioridad impostergable: asegurar la salud y calidad de vida infantojuvenil.

Dr. Roberto J. M. Mateos

Exprofesor Titular de Pediatría, Universidad Nacional de La Plata Buenos Aires, Argentina

http:/ / dx.doi.org/10.5546/aap.2021.148

Texto completo en inglés:

http:/ / dx.doi.org/10.5546/aap.2021.eng.148

Cómo citar: Mateos RJM. Prioridad impostergable: salud y calidad de vida infantojuvenil. Arch Argent Pediatr 2021;119(3):148-149. 